model which imitates with remarkable exactness the phenomena of amoboid movement; while the suggestion that such movement falls into the same category as the change in surfacetension at the boundary between two not-living liquids with change in the constitution of either, is a most important step in the "explanation" of contractility in general.

Here then is a phenomenon which had for years been rendered more olsscure by the attempt to fix upon one of its two universal antecedents as its effective "cause"; while some kind of explanation was at once forthcoming when both antecedents were taken into account. It would be easy to multiply examples of this kind; but perhaps the foregoing may suffice.

I would only now reiterate my hope that in trying to make plain my own position I have not in any way misrepresented that adopted by Prof. Lankester. W. F. R. WELnON.

Marine Biological Laboratory, Plymouth, July I8.

IT appears to me that Prof. Weldon's argument, referred to in NATURE of July 16 (p. 245), is accurately represented in the following illustration. It might be an established fact, although it is not in reality, that there was a constant correlation between baldness and short-sightedness. Suppose that it were so, and that in a country where conscription was enforced, short-sighted men were exempt from military service; that is to say, let us suppose that a test was applied to the eyes of all men at a certain age, and that those whose vision was not normal were rejected and allowed to return to the peaceful pursuits of civilian life. These rejected men would, on the hypothesis, be all more or less bald, and according to Prof. Weldon's position, it would be quite as correct to say that they were not in the army because they were bald, as to say they were rejected on account of myopia. Now it is quite true that the officers of the army medical staff might save themselves trouble by rejecting all bald-headed men, because, on the hypothesis, all such men would be short-sighted; but it would be obviously wrong to conclude that a good development of hair was essential to military efficiency.

Prof. Weldon argues that it is enough to prove that individuals of a species are selected according to a certain character, and that it is unnecessary to discover whether survival depends directly on this character, or on some other with which it is correlated. He seems to have concentrated his attention on the attempt to demonstrate directly the occurrence in nature of individual selection, in this peculiar sense, and to be tem. porarily indifferent to all other questions.

Prof. Lankester suggests that specific characters would be explained if it were proved that they were correlated with adaptive characters. It is of course perfectly true that if there were such constant correlations, then the survival of adaptive variations would involve also the survival of the indifferent characters connected with them. But the difficulty is to prove that in many cases there are any important differences of adaptation between allied species. It is easy enough to define the specific differences and specific characters; but to find any differences which correspond to differences in the mode of life, is often exceedingly difficult. It is true we find in most cases some differences in the conditions of life of closely allied species, but we do not usually find peculiarities of structure which can be said to be adapted to those differences. Who, for instance, can say what adaptation is present in the pilchard or sprat differentiating either from the other or from the herring? The question, therefore, is not whether indifferent specific characters are correlated with useful characters, but whether species of a single genus are distinguished from one another by any characters which can be proved to be useful or adaptive. The tongue and hyoid of the wondpeckers are beautiful adaptations; but are there any differences of selection value between one species of woodpecker and another? The denial of the utility of specific characters means, not merely that some specific characters are indifferent while others are adaptive, but that adaptations are not in the great majority of cases distinctive of species at all. Therefore, as the late Mr. Romanes often ably demonstrated, natural selection is not a theory of the origin of species, but only a theory of the origin of adaptations. The further objection, that a theory of selection is only of secondary importance in comparison with a theory of the origin of variations, I will not enter upon on this occasion.

J. T. CUNNINGHAM.

College of Surgeons, July I 7 .

\section{The Position of Science at Oxford.}

WiLL you allow me a few lines in which to express my entire agreement with your recent article on this subject, if only to em. phasise the fact that I am not the author of the article, and that the opinions there expressed are not those of an isolated individual. The reason for the comparative neglect of natural science at Oxford is that, however well-disposed some individuals may be, the college tutors and lecturers as a rule dislike it. They dislike it for two reasons. First, because it cannot be taught in the college parlours called lecture-rooms ; and second, because they are, as a rule, ignorant-owing to their own defective education--of the nature and scope of the immense field of study comprised under the head "natural science." They do not know either the enormous educational value of natural science, or its vital importance to our national life and development.

And lastly, if they did know, there is no conceivable motive which could operate so as to induce them to sacrifice some of the rewards and educational domination, which are at present enjoyed by the long-established classical and historical studies, to newer lines of work in which the present beneficiaries and their academic offspring can have no share.

The situation is a "dead-lock," and only an intelligent Parliamentary Commission (if such is possible) can put matters on to a fair and healthy basis. Probably the scandal of the present paralysis of our beloved Oxford will have to become even greater and more outrageous than it is at this moment, before the necessary remedy is applied.

But happily the vitality of Oxford is indestructible. The misused and monopolised resources of Oxford will assuredly some day be devoted to the true purposes of a great University. E. Ray Lankester, Linacre Professor, Oxford.

THERE are some points in the article on this subject in NATURE of July 9, which call for comment. The defects pointed out are not, I believe, due to the causes mentioned by your correspondent. The fault lies mainly in the public schools. The lower forms of public schools are, as a rule, mainly classical, the division into sides, classical, modern and science, only beginning when a boy has finished about half his school career. The choice of sides is chiefly left by the parents to the masters, and since in the lower forms these masters have, as a rule, little sympathy with any kind of work which is not purely classical boys of ability are drafted as a matter of course into the classical side. The boys who enter the science side are often the failures of the classical side, and unless special care is taken by the science masters, even they are kept at classics until it is hopeless to make them into respectable science scholars. Naturally there are many exceptions ; some clever boys have enlightened parents, and others, early developing a taste for scientific matters, persuade their parents to allow them to give up the dead languages. There are also some classical men who admit that other subjects than their own have educational value. But the rule is for the able boy to be kept at classics, while his less favoured brother is sent to science. I know that this is the case at the five public schools with whose working I am familiar, and I have little doubt that the science masters of other public schools have the same experience. Occasionally able boys are recruited from the modern side, and it is these boys who are practically shut out from Oxford. Inowever small the knowledge of Greek required for passing responsions may seem to a classical man, it is no light matter for a boy who has it all to learn in little more than a year, and who has much other work to do during the time. At Cambridge the necessary knowledge of Greek is almost nominal, and it is a pity it is not abolished altogether. If both Universities would substitute a good knowledge of German-so necessary for every scientific student-for the very imperfect and quite useless modicum of Greek which they now require, it would result in a great saving of time to many science students, and ultimately in raising the science standard at both Universities.

\section{H. B. BAKER.}

IN your article on "Science at Oxford," in NATURE for July 9, you say: "It may be oljected that every public school has one or more science masters of tried capacity, and that science is a compulsory subject in nearly all."

The first part of this statement may be correct, but I venture to demur to the second. Certainly at one school I could name,

$$
\text { NO. I 396, roL. } 54]
$$

